\title{
LA JUSTICIA TRANSICIONAL: ¿UN PASO HACIA LA PAZ?*
}

\author{
Milcíades Vizcaíno G.**
}

\begin{abstract}
Resumen: La justicia transicional es un asunto complejo, por cuanto encierra múltiples aspectos no solo conceptuales sino en relación con su contexto. Este artículo se propone desarrollar la tesis de que la justicia transicional es el núcleo de la negociación entre el Estado y las fuerzas insurgentes, por cuanto define la justicia, la verdad, la reparación y la no repetición; pero ella es creíble si, y solo si, es aplicable y aplicada. Los argumentos son tres: primero, los acuerdos sobre justicia transicional son controversiales; segundo, las tendencias del pasado reciente anuncian inseguridades sobre las expectativas anunciadas, y, tercero, en las circunstancias actuales, la "no repetición" es frágil por las probabilidades de reincidencia que frenaría la restitución de derechos y de deberes de parte del Estado y de los actores directos.

Palabras clave: Justicia transicional; Conflicto armado; Guerrillas; Paramilitares; Estado; Colombia.
\end{abstract}

El presente texto corresponde a la ponencia que se presentará en el Panel sobre Justicia Transicional de las XXXVII Jornadas Internacionales de Derecho Penal "Problemas actuales de la justicia penal" de la Universidad Externado de Colombia.

* Sociólogo colombiano, con Maestría en Educación en la especialidad de Investigación Socioeducativa; docente universitario por 44 años; en la actualidad es investigador y coordinador del grupo de Investigación Prometeo, en la Universidad Cooperativa de Colombia, Sede Villavicencio, Colombia. Correo-e: milcíades.vizcaino@ucc.edu.co; milci.vizcaino@gmail.com.Bogotá,Colombia.Fecha de recepción: 30 de junio de 2015. Fecha de modificación: 6 de julio de 2015. Fecha de aprobación: 30 de julio de 2015. Para citar el artículo: Milcíades Vizcaíno G. (2015). "La justicia transicional: ¿un paso hacia la paz?", en Revista Derecho Penal y Criminología, Vol. 36, n. . 100, enero-junio de 2015. Bogotá: Universidad Externado de Colombia, pp. 75-88. DOI: http://dx.doi.org/10.18601/01210483. v36n 100.05 


\title{
TRANSITIONAL JUSTICE: ¿A STEP TOWARDS PEACE?
}

\begin{abstract}
The topics about transitional justice are complex because they encompass multiple aspects within the concept and its context. The purpose of this paper is to develop the thesis that transitional justice is at the core of negotiation between the State and insurgent forces as it defines justice, truth, reparation and non-recurrence; but it is credible if, and only if it is applicable and applied. The arguments are three: First, agreements on transitional justice are controversial; second, the trends of the recent past show disbelief regarding pronounced expectations: and third, due to the current circumnstances, the "non-recurrence" is fragile because of the probabilities of relapse, which slows the restitution to rights and duties from the State and direct actors.
\end{abstract}

Key words: Transitional Justice; Armed Conflict; Guerrillas; Paramilitaries; State; Colombia.

\section{INTRODUCCIÓN}

Se ha repetido una y otra vez, a nivel nacional e internacional, el lugar común de que Colombia ha desarrollado el conflicto armado interno más largo del mundo ${ }^{1}$. La relevancia está no solo en la duración sino, sobre todo, en la lista de horrores. Según el Centro Nacional de Memoria Histórica, se han producido 5,7 millones de víctimas de desplazamiento forzado, 1.982 masacres, 220.000 muertos (de ellos, el $80 \%$ civiles inermes y el $20 \%$, combatientes), más de 25.000 desaparecidos y casi 30.000 secuestrados (CNMH, 2013). Todos los colombianos hemos sido "perdedores" (PNUD, 2003) en esta guerra que "se hizo cotidiana [y en la cual] la mayoría de quienes la sufren son personas anónimas" (CNMH, Op. cit.: 18). No es un "pasado remoto" sino "una realidad anclada en (el) presente", como dice el informe, sobre la cual es posible y deseable actuar como "una tarea ineludible en el contexto internacional" (Álvarez y Rettberg, 2008). Poner fin al conflicto armado interno y a sus resultados contundentes es una victoria que marcará un hito en la historia del país.

En este ambiente, hablar de justicia transicional es un avance significativo en la medida en que recoge la experiencia anterior de las normas expedidas para la reinserción de grupos armados vinculados al paramilitarismo y a desmovilizados individuales de grupos guerrilleros, al mismo tiempo que desarrolla nuevos planteamientos coherentes con dos instancias: una nacional para responder a las necesidades de superación del conflicto armado, y la otra para seguir lineamientos internacionales. En esta fase del proceso de negociaciones en la mesa de La Habana con las FARC, y luego con el ELN

1 Ver NAsi y Rettberg (2005); SAndoval y Martínez (2010); CÁRITAS, Cooperación Internacional (2010); Vinyamata y BenaVides -eds.- 2011); Albert (2004). 
en su tratamiento específico, se requiere concluir la agenda cuyos resultados han de ser legitimados políticamente por la comunidad nacional e internacional.

La tesis que argumenta este artículo dice que la justicia transicional es el núcleo de la negociación entre el Estado y las fuerzas insurgentes, por cuanto define la justicia, la verdad, la reparación y la no repetición; pero ella es creíble si, y solo si, es aplicable y aplicada. Los argumentos que presento son tres: primero, los acuerdos sobre justicia transicional despejan opciones controversiales; segundo, las experiencias del pasado reciente no anuncian hacia el futuro plena seguridad de conseguir los éxitos esperados, y, tercero, en las circunstancias actuales, la "no repetición” es frágil, porque las probabilidades de reincidencia son altas, ya que está en juego no solo la restitución de derechos sino también de deberes de parte de los actores directos y del Estado.

\section{LA DISCUSIÓN JURÍDICA SOBRE LA JUSTICIA TRANSICIONAL DESPEJA OPCIONES Y SEÑALA UN CAMINO HACIA LA PAZ}

El tema de la justicia transicional tiene un tinte problemático, retador y, al mismo tiempo, inspirador de salidas al conflicto armado interno en Colombia. Las opciones son numerosas e, igualmente, los argumentos. Las definiciones confrontarán el "presentismo" que cierra la lente en vez de abrirla cuando se requiere una mirada al conflicto armado y a su contexto de cara a un futuro deseable. Obviamente están implicados aspectos jurídicos, la incidencia de organismos multilaterales y de la "comunidad" internacional, las víctimas, la reparación, la devolución de tierras y bienes y el sanar muchas heridas para emprender un camino firme hacia la esperada paz.

El acuerdo sobre justicia transicional incluye, por ejemplo, el fin del conflicto representado en la dejación, entrega o suspensión del uso de las armas, la verdad y la reparación a las víctimas, y con ellas la memoria histórica y la promesa de no repetición, así como la construcción de un ambiente en el cual sea posible practicar la democracia en medio de la diversidad y de la convivencia entre conciudadanos. El qué, el cómo, el quantum y el quiénes son líneas gruesas de un plan de acción como compromiso colectivo hacia la consolidación de la paz. No es todavía la paz sino el camino decidido hacia ella.

La terminación del conflicto armado es un asunto práctico, urgente de resolver por la sensibilidad que ha despertado y es deseable que asuma la condición de inevitable. Si fuere así, las firmas, las constancias, la alta exposición a los medios masivos y la buena voluntad en un momento de euforia son solo algunos elementos de visibilidad que no alcanzan a ser suficientes. El proceso de desactivar el conflicto armado será largo y penoso para víctimas, para victimarios y para la población que ha asimilado riesgos y se ha construido para sí representaciones sociales nefastas para la convivencia ciudadana. Es allí donde la justicia transicional mide sus posibilidades, y también desborda sus límites jurídicos y políticos, las opciones de explicación o de 
justificación y los debates epistemológicos y teóricos para constituirse en un hecho histórico-social y cultural. Es una mirada al mañana, es decir "al día después". Por ahora, porque no somos profetas, como dice MichAEL LöwY (2010), aprendemos que "cada segundo es la puerta estrecha por cual puede venir la salvación" que será un país y una sociedad en paz. Los medios masivos tejen una historia en un "cuadro a cuadro", en el día a día de los hechos, que corresponde a una producción que no se muestra en toda su dimensión.

\section{LAS RECIENTES EXPERIENCIAS EN COLOMBIA MUESTRAN LA FRAGILIDAD ORGANIZACIONAL Y POLÍTICA TANTO DE LOS GRUPOS INSURGENTES COMO DEL PROPIO ESTADO}

Como dice el informe de Memoria Histórica, "Colombia apenas comienza a esclarecer las dimensiones de su propia tragedia. La mayoría de sus ciudadanos aún no tiene una conciencia clara de los alcances que ha tenido la guerra interna, de sus impactos y sus mecanismos de reproducción" (CNMH, Op. cit.: 17). Se requiere una pedagogía insistente y persistente para la difusión de los procesos, pero, ante todo, para lograr un anclaje de los avances que responden a la urgencia de superar los conflictos para armar la paz.

Un punto central es la no repetición. Ella consiste en la seguridad que tienen los ciudadanos de que la barbarie que ha significado el conflicto armado agenciado por los actores múltiples no regresará a sus vidas. En este punto es fructífero lanzar una mirada a la historia reciente para aprender de ella y fortalecer la representación colectiva de la urgencia de voltear la página de una vez por todas. Desde 1958 hasta el presente se han conformado oficialmente 15 comisiones de estudio e investigación sobre el fenómeno de la violencia, de ellas 12 de carácter nacional y tres locales (Comisión Histórica del Conflicto y sus Víctimas, 2015). Muy pertinente sería volver sobre trabajos académicos como el de JEFFERSON JARAMILlo, Pasados y presentes de la violencia en Colombia. Estudio sobre las comisiones de investigación (19582011). Es pertinente, igualmente, repasar La violencia en Colombia, de ORLANDO FAls Borda, Germán GuZmán Campos y Eduardo Umaña Luna (1962). La muerte de ORlando Fals Borda, el "sociólogo del compromiso", como lo llamó GonZalo CATAÑo (2008: 79-98), ocurrió hace siete años. Los resultados del estudio fueron polemizados por la prensa, los poderes civiles, eclesiásticos y militares y el legislativo, hasta desprestigiarlo y llevarlo al olvido (SÁNCHEZ, 1999: 561-575). En aquel momento de la historia no se contaba con periodistas independientes, la televisión aún no había llegado plenamente a los hogares y los directores de los medios permanecían fieles a la oficialidad. La investigación sobre la violencia en Colombia daba a conocer que "en sus campos la gente se mataba a machete, que en ellos los niños eran lanzados al aire y recibidos por las bayonetas de los armados, las mujeres eran violadas a veces por dos, tres e incluso cuatro hombres y que todo esto era auspiciado por los partidos Liberal y Conservador" (JIMÉNEZ H., 2012). Lo mismo que sucedió a 
Prometeo, encadenado por los dioses por haber enseñado a los hombres los poderes del fuego, los investigadores fueron vilipendiados por contar la verdad de la violencia. CAMILO UMAÑA, nieto de EdUARDO UMAÑA, recordó sobre las consecuencias de la obra: "A mi abuelo lo insultaron graciosamente con las nominaciones de 'libre pensador extremista' o 'abogado volteriano y enciclopedista'. A monseñor GuZMÁN no se le bajó de 'capellán de los bandoleros' y, jugando con su título, le llamaron 'Monstruo Guzmán'. El mismo ingenio fue usado para el profesor FALS BORDA, a quien le tildaron de "Falso Borda"" (ídem). Los relatos se convirtieron en tema de opinión y de controversia pública y muy pocos atendieron el mensaje. Según GoNZALO SÁNCHEZ, el director de la Comisión para la Memoria Histórica, ese mensaje era fundamental: si la lección hubiera sido atendida, "algo sería diferente" (SÁNCHEZ, 2012, citado por JIMÉNEZ), pero fue oscurecido por los intereses que provocaron el conflicto bipartidista (SÁNCHEZ G., 2004). El "pacto de silencio", convenido en la oscuridad y rescatado por DANIEL PÉCAUT (2010: 79), consistió en que "las élites acuerdan lanzar un velo sobre su responsabilidad en la Violencia. Ni los líderes nacionales, como LAUREANO GóMEZ, ni los cuadros locales que tomaron parte en ella tienen que rendir cuentas". Pero no solo evitan la rendición de cuentas, sino que les ha permitido "mantener su influencia, impidiendo cualquier tipo de concentración excesiva del poder en manos del Estado central, y han garantizado el control de la mayor parte de las clases populares y medias, privándolas de recursos propios de expresión política, que hubieran podido amenazar las instituciones", dice el mismo PÉCAUT (ídem: 42). La perspectiva es oscura porque "Colombia no ha podido jamás sanear los efectos de otra experiencia masiva de desplazamiento, como fue la de la Violencia de los años cincuenta. Todo hace pensar que se necesitarán varias décadas para saldar cuentas con la experiencia actual, que pesará sobre otras tantas generaciones" (ídem: 23) 2 .

Otro evento trágico en la historia reciente fue la firma de un acuerdo del gobierno del presidente BELISARIO BETANCUR con las FARC, en mayo de 1985. Las FARC organizaron la Unión Patriótica y luego 3.800 de sus militantes fueron asesinados uno a uno, por lo cual el Estado posteriormente fue condenado a resarcir a las víctimas y a hacer una manifestación pública de perdón. ¿Aprendimos la lección? La historia pasada nos ha mostrado que no; ojalá la historia que ahora se construye nos presente el sí de que podemos aprender la lección en favor de la apertura democrática en la diversidad.

Luego vinieron las desmovilizaciones del M-19, el Quintín Lame, el PRT, el EPL y demás grupos insurgentes. El estigma creado desde la institucionalidad política ha sobrevivido a pesar de que los reinsertados dieron pruebas de su conexión con la vida civil y política institucionalizada. Aún hoy, después de 25 años, el estigma negativo es un arma política de sus eternos contradictores. Esta es otra lección para aprender.

2 Se refiere a la investigación de María Teresa Uribe de Hincapié (1992). 
Después vinieron las desmovilizaciones de los paramilitares. Una conclusión preocupante es la que presentó DANIEL PÉCAUT (1999), en un evento internacional cuando se refería a los paramilitares: "No se contentan con matar, sino que [...] mutilan los cuerpos con el fin de demostrar que están dispuestos a destruir hasta los últimos restos de lo que es un humano"3. Sobre ellos se desarrolló una normatividad que inauguró el ingreso de la justicia transicional en el país y que ha provocado satisfacciones e insatisfacciones a granel.

La Ley 975 de 2005 se conoció como la norma central de justicia y paz que fue un marco jurídico para la desmovilización, más que un marco de justicia transicional que tuviera como su centro de gravedad a las víctimas. Los datos son contundentes: la cifra de combatientes rasos oscilaba entre 19.000 y 35.000 , lo que significa una incertidumbre sobre el quantum de la reintegración. Este primer aspecto se complementa con el siguiente: los combatientes se reintegraron a la vida civil, en aplicación de la Ley 782 de 2002, sin pagar un solo día de cárcel, sin contar la verdad y sin reparar a las víctimas, lo cual es una amnistía disfrazada. El tercer aspecto es que aproximadamente 4.700 militantes paramilitares y 500 de otros grupos insurgentes fueron postulados por el gobierno para ser beneficiados por una pena entre cinco y ocho años asociados a la confesión de verdad y compromiso con la reparación. De todos ellos, 2.800 postulados se encuentran activos en procesos penales, con cerca de mil privados de la libertad; en siete años de vigencia de la norma hay cuatro condenas (CUERVo, 2013). Este es un indicador claro de impunidad generalizada.

Una fuente diferente muestra datos según los cuales más de 2.000 militantes del paramilitarismo que se desmovilizaron todavía esperan un juicio en comparación con las siete sentencias que están vigentes. Pero lo más profundo es que "el fenómeno paramilitar no fue solamente criminal, sino también social y político. Sus tentáculos se extendían en todas las áreas de la vida social, política y económica [...] Y eso significa que las investigaciones deberían incluir a personas de los sectores financieros y políticos, aquellos sin los que hubiera sido imposible que existieran este tipo de organizaciones" (ICJT, 2012).

Otra fuente menciona que en fosas fueron encontrados casi 5.000 restos de desaparecidos y contra los más de 4.000 postulados se han producido cerca de veinte sentencias en relación con el esclarecimiento de "más de 40.000 crímenes que afectaron a 50.000 víctimas" (Semana, 2015). Basados en estos elementos, y en una mirada hacia adelante, uno de los temas controversiales es la no repetición.

3 La pérdida de los derechos, del significado de la experiencia y de la inserción social. A propósito de los desplazados en Colombia. Ponencia en el Foro Internacional "Desplazados internos en Antioquia", organizado por el Comitato Internazionale per lo Sviluppo dei Popoli (CISP), Italia. Estudios Políticos 14, Medellín, enero-junio de 1999. 


\section{LA PROMESA DE “NO REPETICIÓN” ES FRÁGIL DEL LADO DEL ESTADO Y DE LOS INSURGENTES}

¿Cuál es la garantía que tienen los ciudadanos de la no repetición? ¿Cuál va a ser la responsabilidad del Estado y de los grupos insurgentes? Iniciemos con una pregunta: ¿dónde estaba el Estado mientras el conflicto se fraguaba, se recrudecía, se prolongaba y dejaba una estela de víctimas que hoy esperan verdad, justicia y reparación? La pregunta es pertinente desde el inicio del conflicto hasta la actualidad. Inicialmente, el conflicto se ha ensañado sobre todo "en la 'periferia' campesina y ha sido marginal al sistema político colombiano” (PNUD, 2003: 21). La imposibilidad de la derrota militar por parte del Estado, desde los bombardeos de El Pato, y la incapacidad de la guerrilla de las FARC de vencer militarmente al Estado, separó la geografía nacional: el Estado se concentró en las ciudades y en regiones de tradicional desarrollo económico y político, y abandonó el territorio de frontera en el cual la guerrilla organizó su propio Estado, de facto, como "Estado embrionario" pero que se consolidó con la apropiación de tierras.

Cuando la expansión de las FARC penetró en los dominios del Estado fue atacada por las autodefensas con la complacencia o apoyo del Estado hasta que los límites entre regiones se hicieron borrosos por la alta movilidad de los frentes armados de uno y de otro lado de la confrontación (ídem: 49). Finalmente, el resultado ha sido "una guerra de perdedores" (ídem: 81). Perdieron las guerrillas, perdieron las autodefensas, perdió el Estado y perdió la población civil. En la confusión provocada, las confrontaciones fueron de ciudadanos contra ciudadanos (URIBE, 2011) ${ }^{4}$. Los hechos que hilvanaron el proceso se escondieron tras "una negación colectiva" que consistió en silenciar la gravedad que tomaba el conflicto armado.

El Estado ha configurado vacíos que se presentan, al menos, en tres formas: la primera son los espacios empleados por sus funcionarios que están llamados a cumplir y hacer cumplir las normas, pero no lo hacen, y los ciudadanos se perjudican por su acción o por su omisión. La segunda forma ocurre cuando la norma es expedida pero no se cumple por la suplantación de intereses en su contra. En este ambiente, gana terreno la cultura del "vivo", del astuto, del sagaz que apela a medios ilegítimos para alcanzar objetivos con el uso de su "inteligencia social" de sobrevivencia. La tercera forma aparece cuando se expide una norma que no soluciona las expectativas y se buscan alternativas que la sustituyan en la práctica, así sea enfrentándose con el Estado o, en todo caso, por fuera de su control y legitimidad. Aparece una estructura dual claramente definida, en sub-universos cuasi-autónomos, con continuidad y permanencia y un grado reconocible de legitimidad hacia dentro: las élites consideran al Estado como parte de su patrimonio y lo usan para beneficio privado y los contrapoderes generan las condiciones para erigirse con funciones de Estado. Cuando los agentes

4 También puede consultarse a WALDMAnN (2007). 
del Estado perciben contradictores, el ámbito político se desplaza hacia el militar y policial que es encargado de ponerles freno y contener su eventual acción. En estas circunstancias, los ciudadanos en la periferia del poder político son convocados a zanjar sus diferencias y producir convivencia por su propia cuenta.

Por las razones mencionadas, el Estado colombiano no es solo "anómico" por cuanto deja de cumplir las funciones básicas o complementarias que se esperan de él de acuerdo con la tradición jurídica, política e histórica, como son la integración, la regulación y el control, sino que se ha producido su desinstitucionalización generalizada, es decir, ha caído en una "anomia crónica", lo que significa la pérdida de sentido para sí mismo y para los ciudadanos a quienes representa (WALDMANN, 1997 y 2004) ${ }^{5}$. En este ambiente, es fácil encontrar rasgos de desviaciones funcionales y estructurales que alejan la posibilidad de cumplimiento cabal de su tarea. No se desconoce otra línea de interpretación que es la gubernamentalidad entendida como estrategia de gobernar la nueva cuestión social en América Latina (GIAVEDONI, (2012). Sin embargo, en esta presentación se adopta la primera postura teórica.

El otro actor central son los paramilitares que sobrevivieron con el apoyo de sectores instalados en el Estado desde el cual ejercieron como francotiradores, contribuyeron a deslegitimarlo y a llevarlo por el camino de la anomia crónica. Su estrategia de infiltración dentro de los órganos del Estado es una evidencia claramente demostrada. Por su parte, la guerrilla de las FARC viene de experiencias pasadas en las cuales ha aprendido la desconfianza, el resentimiento, la retaliación, la búsqueda de argumentos para resistir y para atacar, y muestra como victoria que el Estado no pudo derrotarla. El ELN se ha considerado como un grupo minoritario, con escaso poder de confrontación, pero ha dado muestras de acciones armadas o de atentados eficaces frente a la inerme población. La acción insurgente ha contribuido, sin duda, a fortalecer la anomia crónica que padece el Estado.

La organización jerárquica de las FARC, y también del ELN, fundamentada en la estructura militar consolidó para sí la dominación/obediencia en el desarrollo de su proyecto estratégico encaminado a la toma del poder por las armas. De manera que no experimentó la democracia en ninguna de sus formas, ni una extensión a estructuras diferenciadas en educación, economía, política, salud y otros servicios. El paso de la desmovilización supone que la organización, como sus militantes, se convierten en $E X^{6}$, que significa abandono total del antes para pasar a un estadio diferente en el cual son reconocidos como conciudadanos. Llegar a la inserción colectiva a la sociedad significará que sus ideales desaparecen y sus militantes se adaptan a la organización del Estado, lo cual representa un cambio en profundidad, una revolución interna en

5 También se puede consultar: Waldmann (2006), Vizcaíno G., M. y Vizcaíno G., G. P. (2015).

6 La referencia directa es al trabajo de Fuchs E. (1989). 
los individuos y en la colectividad que ya no será FARC con objetivos de toma del poder sino de convivencia social pacífica.

En todos los casos, la experiencia del conflicto armado interno dice que nos encontramos con hombres y mujeres "vulnerables, con múltiple problemática personal y social, previa y posterior al proceso de incorporación a los grupos armados" (DE LA ESPRIELlA y FALLA, 2009: 230-247). También debemos afirmar que esa problemática no está solo en los alzados en armas sino en civiles que ideológicamente han asumido una de dos posiciones: o son guerreros con los medios masivos y con sus poderes políticos, o se camuflan en la corrupción que corroe al Estado y le produce deslegitimación cuando requiere fortaleza para liderar las tareas del posconflicto. De esta suerte, la anomia crónica limita el poder del Estado cuando se espera de él fortaleza para cumplir con los acuerdos pactados. Los aparentes aliados del Estado se convierten en victimarios con rostro de eficiencia de cara a la ciudadanía.

Es en este punto en donde planteo la hipótesis de que el Estado, con sus funcionarios y aliados políticos, no está en plenas condiciones saludables para asumir los retos del posconflicto. Requiere un proceso de limpieza que le ayude a superar la raíz de sus debilidades, vale decir, cortar los circuitos de la corrupción, del uso de los bienes públicos para beneficio privado, de mediar a favor de intereses de unos en contra de otros y, al contrario, dar prioridad a la solución real de los problemas de la población: empleo, salud, vivienda, educación, seguridad, convivencia, en medio de un ambiente de paz.

Hay que llamar la atención y cerrar el camino a experiencias pasadas que no fueron eficaces. Al contrario, ampliaron el camino para nuevas confrontaciones. Un ejemplo fue la "desmovilización promovida por el expresidente ÁlvARO URIBE VÉlEZ durante su gobierno en Colombia (2002-2010), [que] fue más un instrumento para derrotar a las guerrillas (particularmente a las FARC-EP), que un paso en la solución del conflicto armado del país que proveyera a los excombatientes posibilidades reales de desmovilización y reintegración a la vida civil" (CÁRDENAS S., 2011) ${ }^{7}$. Esta es una conclusión de una tesis de Maestría en Historia sustentada en la Universidad Nacional de Colombia y asesorada por científicos sociales en el campo de la investigación histórica. En consecuencia, no se previeron tratamientos psicosociales que contribuyeran a una reintegración eficaz a la sociedad y, desde luego, a la no repetición. Tampoco se emprendió una acción de revisión del Estado para deshacerse de sus propias debilidades que se han prolongado hasta la actualidad y se proyectan al inmediato futuro. Los ejemplos sobreabundan ${ }^{8}$. Una reflexión sobre este contexto permite concluir que "Colombia es un Estado paradójico, de inestabilidad estable y estabilidad inestable" (KRUIJT y KoONINGS, 2008).

7 Ver también Pinto, Vergara y La Huerta (2002).

8 Ver García-Peña J., D. (2005), DuQue et al. (2007), LosAdA, R. (2006). 
En conclusión, la justicia transicional es una recuperación de derechos para cuantos han sido violentados dentro del conflicto armado. Pero, al mismo tiempo, porque lo supone y no es evidente su existencia plena, es una recuperación de deberes de los victimarios que deben garantizar verdad, justicia y reparación respecto de los hechos pasados y no repetición hacia el futuro. Esto incluye al Estado por cuanto él toma las riendas de los procesos hacia el futuro, lo que significa que con las normas vigentes ejerce el control, la dirección y la aplicación de su poder sobre la población y sus territorios. Para poder cumplir adecuadamente los deberes, el Estado debe recuperar sus poderes plenos. En consecuencia, hay que prever las eventualidades descritas y definirlas como objetivo para ser superadas con el compromiso de todos, combatientes o no, nacionales e internacionales, que ejercerían una veeduría proactiva y un control legitimado. Solo así estará asegurada la eficacia de la justicia transicional para entrar en el dominio de la paz. De ahí en adelante el reto es permanecer en ella y con ella, en un ambiente de democracia renovada.

\section{BIBLIOGRAFÍA}

Albert G., M. C. (2004). El conflicto en Colombia ¿Es posible la paz? . Universidad de Alicante: Instituto Universitario de Desarrollo Social y Paz. Febrero.

Álvarez, S. y Rettberg, A. (2008). “Cuantificando los efectos económicos del conflicto: una exploración de los costos y los estudios sobre los costos del conflicto armado colombiano", en Colombia Internacional 67, Jun.

ÁlvARO R., M. (2008). “La parapolítica: la infiltración paramilitar en la clase política colombiana”, en Ánfora Política 15 (24), enero-julio.

BAILEy, N. A. (1967). "La Violencia en Colombia", en Journal of Inter-American Studies 9, October, 561-575.

CÁrdenas S., J. A. (2011). Los agujeros negros del desarme. La desmovilización individual en el gobierno de Álvaro Uribe Vélez 2002-2010. Bogotá: Universidad Nacional de Colombia, Facultad de Ciencias Humanas, Departamento de Historia, (Tesis de Maestría en Historia).

CÁRITAS, Cooperación Internacional (2010). Participación en la construcción de la paz. Protección de los derechos de las víctimas en Colombia. Madrid: Caritas Española Editores.

CATAÑo, G. (2008). "Orlando Fals Borda: sociólogo del compromiso”, en Revista de Economía Institucional 10(19), segundo semestre. 
Chaparro A., A. (2009). "Estado y justicia transicional: el caso de las AuC", en Chaparro A., A. y Galindo H., C. (2009). Génesis y transformaciones del Estado Nación en Colombia. Una mirada topológica a los estudios sociales desde la filosofía política. Bogotá: Ediciones Universidad del Rosario.

CNMH -Centro Nacional de Memoria Histórica- (2013). ¡Basta ya! Colombia: memorias de guerra y dignidad. Disponible en http://www.centrodememoriahistorica. gov.co/micrositios/informeGeneral/descargas.html. Consultado el 2 agosto de 2015.

Comisión Histórica del Conflicto y sus Víctimas (febrero de 2015). Contribución al entendimiento del conflicto armado en Colombia. Disponible en https://www.mesadeconversaciones.com.co/sites/default/files/Informe\%20Comisi_n\%20Hist_rica\%20 del\%20Conflicto\%20y\%20sus\%20V_ctimas.\%20La\%20Habana\%2C\%20Febrero\%20 de\%202015.pdf E:\AppData\Local\Packages\Milciades\Downloads $\backslash$ Contribuci $\tilde{A}^{3} n$ al entendimiento del conflicto armado en Colombia - Comisi $\tilde{\mathrm{A}}^{3} \mathrm{n}$ Hist $\tilde{\mathrm{A}}^{3}$ rica del Conflicto y sus VÃctimas.pdf. Consultado el 25 julio de 2015.

CuERvo R., J. I. (2013). “La justicia transicional no pegó”, en El Espectador, 4 abril.

De la Espriella, R. y Falla, J. V. (2009). "Reflexiones sobre la atención en salud mental de desmovilizados de grupos armados en Colombia", en Revista Colombiana de Psiquiatría, 38(2), p. 230-247.

DuQue, L. F. et al. (2007). "Similitudes y diferencias entre miembros de las Autodefensas Unidas de Colombia, agresores severos y controles comunitarios en Medellín”, en Revista Facultad Nacional de Salud Pública 25(2), July/Dec.

FAls Borda, Orlando; Germán GuZmán CAmpos y EduARdo Umaña LunA (1962). La violencia en Colombia. Bogotá: Universidad Nacional de Colombia (reimpresión en Bogotá, Editorial Iqueima, 1963).

Fuchs E., Helen Rose (1989). Becoming an Ex: The Process of Role Exit. Chicago: University of Chicago Press.

García-PeÑa J., D. (2005). "La relación del Estado colombiano con el fenómeno paramilitar”, en Análısis Político 53, enero-marzo.

Giavedoni, J. G. (2012). "Del Estado en crisis a la crítica del Estado. Diálogo en torno a la perspectiva del Estado y la gubernamentalidad en el análisis de la nueva cuestión social en América Latina", en Revista Mexicana de Ciencias Políticas y Sociales 57(214), enero-abril. 
ICTJ -Justicia, verdad, Dignidad- (2012, 8 mayo). En profundidad: El Proceso de Justicia y Paz en Colombia. Disponible en https://www.ictj.org/es/news/en-profundidad-el-proceso-de-justicia-y-paz-en-colombia. Consultado el 3 agosto de 2015.

Jaramillo, J. (2014). Pasados y presentes de la violencia en Colombia. Estudio sobre las comisiones de investigación (1958-2011). Bogotá: Editorial Pontificia Universidad Javeriana.

Jiménez H., J. S. (2012). “La Violencia en Colombia, 50 años después. Medio siglo de un libro valiente", en El Espectador, 23 junio.

Kruijt, D. y Koonings, K. (2008). Colombia, Estado paradójico. Fride, Comentario enero 2008.

LOSADA, R. (2006). "Implicaciones electorales de la reinserción política de las autodefensas en Colombia”, en Papel Politico 11(1), Jan./June.

Löwy, M. (2010). La revolución es el freno de emergencia. Actualidad político-ecológica de WALTER BENJAMIN. Conferencia en L'École de Hautes Études en Sciences Sociales, Paris, 25 abril 2013. Disponible en www.walterbenjaminportbou .cat/sites/ all/files/2010_Loewy_CAST.pdf. Consultado en el 27 julio de 2015.

Medellín, P. (2007). “El paraempresariado ¿Comprando seguridad?”, en El Tiempo, 22 mayo.

Nasi, C. y Rettberg, A. (2005). "Los estudios sobre conflicto armado y paz: un campo en evolución permanente", en Colombia Internacional 62, jul - dic.

PÉCAUT, D. (1999). La pérdida de los derechos, del significado de la experiencia y de la inserción social. A propósito de los desplazados en Colombia. Ponencia presentada en el Foro Internacional "Desplazados internos en Antioquia", organizado por el Comitato Internazionale per lo Sviluppo dei Popoli (CISP), Italia. Estudios Políticos 14, Medellín, enero-junio.

PÉCAUT, D. (2010). "Simbólica nacional, liberalismo y violencias”, en CALDERón, M. T. y Restrepo, I. (eds.). Colombia 1910-2010. Bogotá: Taurus.

Pinto B., M. E.; Vergara B., A.; y La Huerta P., Y. (2002). Diagnóstico del programa de reinserción en Colombia: mecanismos para incentivar la desmovilización voluntaria individual. Bogotá: DNP (Departamento Nacional de Planeación), Dirección de Estudios Económicos, Archivos de Economía. Documento 211, 20 de noviembre. 
PNUD -Programa de las Naciones Unidas para el Desarrollo- (2003). "El conflicto: callejón con salida", en Informe Nacional de Desarrollo Humano para Colombia. Bogotá, septiembre.

SÁnchez G., G. (1999). "La violencia en Colombia”, en Revista Credencial Historia 110 , febrero.

SÁnchez G., G. (2004). “'La violencia en Colombia’, trabajo de GERMÁn GuZMÁn, OrLANDO FALS BORda y EdUARdo UMAÑa LunA. Así se escribió 'La violencia en Colombia'", en El Tiempo, 13 de Julio.

SÁnchez G., G. (2012). Citado por Jiménez H., J. S . (2012). "La Violencia en Colombia, 50 años después. Medio siglo de un libro valiente”, en El Espectador, 23 junio.

SAndoval, L. E. y Martínez B., D. (2010). "Presencia de conflicto armado interno y su efecto en la inversión extranjera directa: Tendencia mundial y perspectivas para Colombia (2001-2007)", en Revista de la Facultad de Ciencias Económicas, $18(1)$, junio 2010.

Semana (2015, 15 marzo). Ocho años de la Ley de Justicia y Paz.

Uribe de Hincapié, María Teresa (1992). Matar, rematar y contramatar, 19481962. Bogotá: Cinep.

Uribe L. M. (2011). “Lo Político en la Guerra Civil Colombiana”, en Análisis Político 72 , mayo-agosto.

VÁsquez M., AinhoA (2014). "La villanía heroica de El Señor de los Cielos en la lucha contra un Estado anómico", en Anagramas: Rumbos y sentidos de la comunicación 13(25), p.107-125.

Vinyamata, E. y Benavides V.(eds.) (2011). El largo camino hacia la paz: Procesos e iniciativas de paz en Colombia y en Ecuador. Barcelona: AECID (Agencia Española de Cooperación Internacional para el Desarrollo - Editorial UOC.

VizCaíno G., M. y Vizcaíno G., G. P. (2015). Ambivalencias del Estado colombiano frente a su anomia crónica (inédito). Capítulo de un libro que proyecta la Defensoría del Pueblo con la Universidad Externado de Colombia.

Waldmann, P. (1997). "Cotidianización de la violencia: el ejemplo de Colombia”, en Análisis Político 32, septiembre-diciembre, pp. 34-50.

WALDMAnN, P. (2004). "Sobre el concepto de Estado anómico”, en BERnEKER, W. L. (comp.) (2004). Transición democrática y anomia social en perspectiva compara- 
da. México: El Colegio de México / Centro de Estudios Históricos: Centro Alemán de Intercambio Académico: Universidad Nacional Autónoma de México, Facultad de Filosofía y Letras.

Waldmann, P. (2006). El Estado anómico: Derecho, seguridad pública y vida cotidiana en América Latina. Madrid: Iberoamericana y Frankfurt am Main: Vervuert Verlag.

Waldmann, P. (2007). Guerra Civil, Terrorismo y Anomia Social.El Caso Colombiano en un Contexto Globalizado. Bogotá: Editorial Norma - Konrad Adenauer Stiftung. 